Research Article

www.jestr.org

\title{
Construction of Intelligence Knowledge Map for Complex Product Development
}

\author{
Yan-jie LV, Gang Zhao*, Pu Miao and Yujie Guan \\ ${ }^{1}$ School of Mechanical Engineering and Automation Beijing University of Aeronautics and Astronautics, Beijing 100191, China
}

Received 15 September 2013; Accepted 23 November 2013

\begin{abstract}
The complex product design and development is an integrated discipline. A lot of knowledge overloads and knowledge trek phenomenon appeared with the raise of product complexity and the explosion of knowledge and information. To improve the utilization efficiency of the knowledge using and shorten the time and effort spent on the Knowledge screening, avoid missing the knowledge, which is required, the paper proposes a method for the intelligence knowledge map construct model based on knowledge requirements and knowledge connection. Analyzing the context information of the user and giving the method of acquiring the knowledge requirement based on the context information and the user's personal knowledge structure. This method can get the knowledge requirements of the users to generate the knowledge retrieval expressions to obtain the knowledge points and then construct the intelligent knowledge map through the analysis of multiple dimensions and using the knowledge related to the development of aircraft landing gear as an example to verify the feasibility of this method.
\end{abstract}

Keywords: intelligent; knowledge map; knowledge requirement; knowledge connection

\section{Introduction}

The development of complex products is a collaborative processes, this process needs the collaboration of design teams of multiple areas to accomplish work under users' needs and enterprise resource constraints, based on knowledge inheritance and reuse. As an intangible resources and production factors [1], the quick discovery and reuse of knowledge is an important way to speed up product development, avoid repetitive error and improve business efficiency. As the application of all kinds of information systems, the raise of product complexity and the growing of knowledge and information, the phenomenon of knowledge overloads and knowledge trek appeared and workers have to spend a lot of time to screen the knowledge to find the knowledge which is needed but find it's hard to do so. To solve these problems, it's important to organize the knowledge reasonable and make sure what kinds of knowledge is useful to which tasks and which people, who know it and who use it and etc.. Knowledge map, as a form of knowledge management, has the function of knowledge navigation and tacit knowledge acquisition [2-4]. It is playing an important role in the knowledge management system [5] to express the knowledgehierarchy and knowledge connection.

As a basic tool of knowledge management [6], knowledge map usually limited to conceptual knowledge map and used in insurance, banking, economic management and etc.. Over the years, articles and papers conducted some research on the principle of knowledge map's construction

*E-mail address: Ivyanjie@126.com

ISSN: 1791-2377 @ 2013 Kavala Institute of Technology. All rights reserved
[7], proposed the methods of the four steps construction of knowledge map, five steps construction of knowledge map and so on to build the knowledge map. In concrete application, literature [8] proposed a method to construct the knowledge map for product development based on metaknowledge and XML visualization. Literature [9] conducted some research on the classification and function of the knowledge map according to the knowledge requirement in the process of product development. For the reason that complex product has a complexity of product structure, involves many fields and tons of knowledge and the different knowledge structure between different workers, different workers has different knowledge requirements and the same worker has different knowledge requirements at the different context. The current knowledge map has the following problems in the application of complex product development process. $\ominus$ The full set of knowledge map is very difficult to construct and involved in poor real-time performance. $\ominus$ The knowledge map isn't satisfy the requirement of different workers to get the knowledge from the same view, for different workers have different requirements.

To solve these deficiencies, this paper proposes an intelligent knowledge map construction method, integrated people, knowledge and context information. By getting the context of the knowledge application to acquire the knowledge requirements of the workers to select the appropriate knowledge for the right worker and build the knowledge maps intelligently from different context view, and finally demonstrate the knowledge map from multiple aspects by $3 \mathrm{D}$ visualization techniques. 


\section{Intelligent knowledge map construction model based on knowledge requirement and connection}

To solve the problem of difficult knowledge map construction of the complex product for involved too many fields and tons of knowledge. This paper proposes an intelligent knowledge map construction model based on knowledge requirement and connection which is shown in Fig.1: $\ominus$ Getting aware of the current activities context information. $\ominus$ Analyzing the context information to acquire the knowledge requirement. $\circledast$ Getting the knowledge directory related to the knowledge requirement.(4)Analyzing the connection between the knowledge and then using the knowledge visualization technology to construct a multidimension knowledge map to do intelligent knowledge navigation according to the co-occurrence of the knowledge.

The key technology of the intelligent knowledge map construction model based on knowledge requirements and knowledge connection are as follows: $\ominus$ Knowledge model integrating context. $\ominus$ Technology of context awareness. $\circledast$ Constructing knowledge retrieval expression based on knowledge requirements.(4)Knowledge retrieval based on the context similarity.(5)Knowledge correlation analysis and multi-dimension knowledge visualization technology.

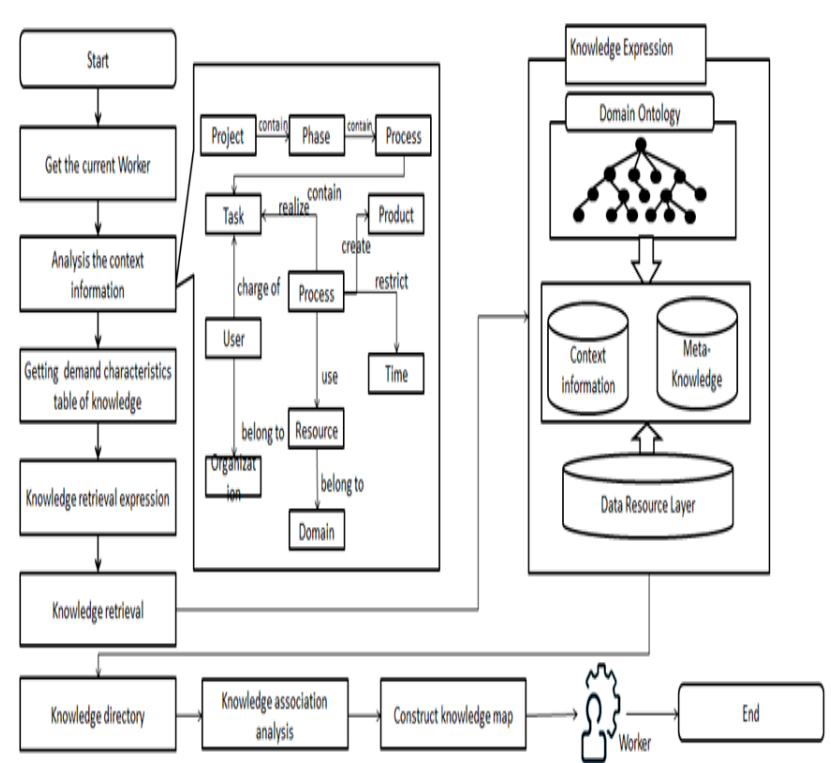

Fig.1. Knowledge map construction model based on knowledge requirement and connection

\section{Knowledge requirement}

The purpose of knowledge management is to improve the efficiency of product development and choose the right knowledge at the suitable time and push it to the worker. Fig. 2 shows the development of complex product design.

The work manager builds the task tree according to the project's needs and assigns it to the workers to finish it. After accepting the task, the worker using his experience to do the work and gets help from the knowledge database when meets difficulties and store the useful knowledge gets from doing the work which isn't exist in the knowledge database at present. Knowledge as the main intellectual resource runs through the whole process in the product development.

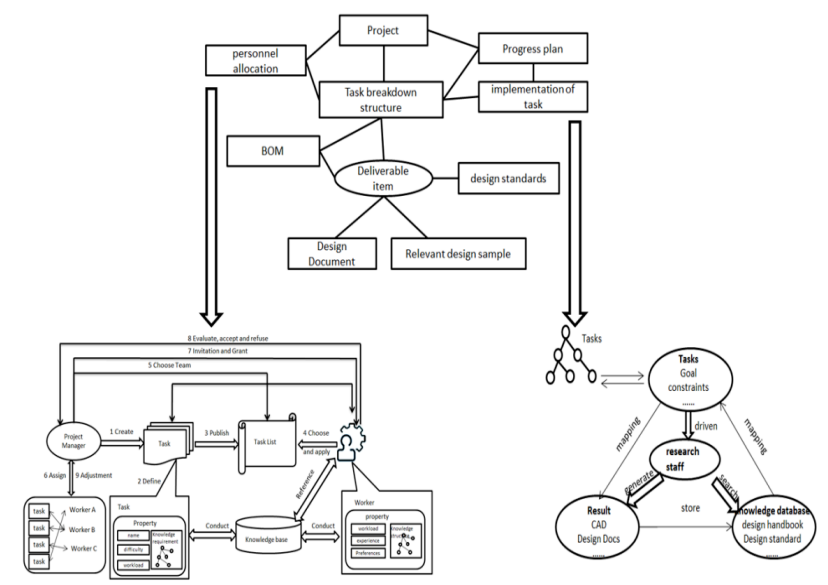

Fig.2. Complex product development process diagram Based on the knowledge

The application of knowledge is based on the knowledge requirement which is decided by the context information of current activities. To obtain the knowledge requirement, the context elements of the task and the product is mainly considered.

The tasks of product development contain the content, constraints of the tasks and so on. The goal of the tasks is to meet the structure requirement and function requirement defined by the tasks. Based on the co-occurrence analysis, the paper built the relationship between the properties of the task and the knowledge topics. The workers get the context information of the task and then through the mappings between the context information and the knowledge topics to obtain the knowledge requirement of the task.

The product structure is constantly improving with the process of task's execution. At first, the product structure has only one node and extended by the worker in the product development process. Therefore, it may be hard for the workers to know what to do when they have no idea of the substructure of the product is going to be. To solve the problem, using the accumulated knowledge from other product's design to construct a product structure model and enriching the node by connecting it to the knowledge coming into being in the previous product design. The process of getting the knowledge requirement of the product structure is shown in Fig.3.

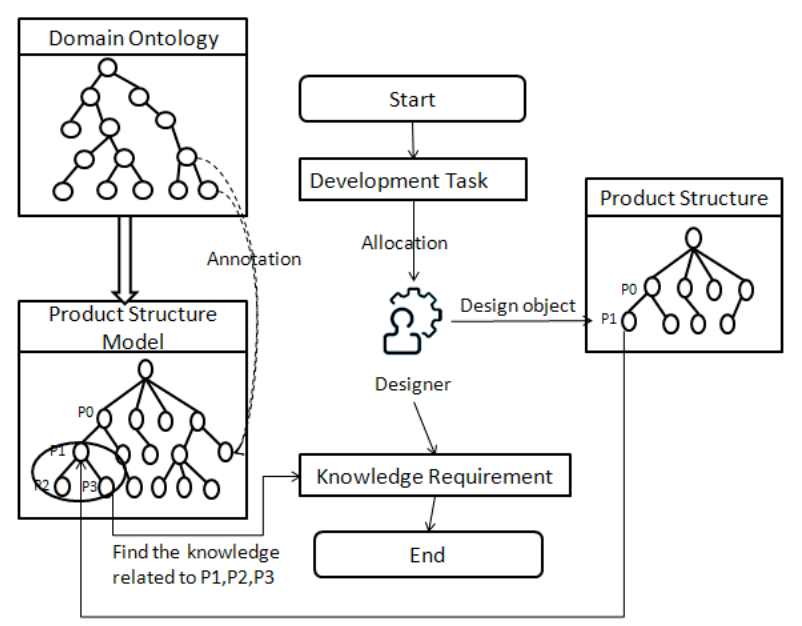

Fig.3. Knowledge Requirements of Product Structure

The knowledge requirement is defined as follows:

$\mathrm{KR}=<$ TaskR, ProductR $>$ 
TaskR and ProductR is the condition, background, environment and other context information related to the task and product structure which can be formalized as: TaskR $=\{\mathrm{t} 1, \mathrm{t} 2, . ., \mathrm{ti}, \ldots \mathrm{tn}\}, \quad$ ProductR $=\{\mathrm{p} 1, \mathrm{p} 2, \ldots, \mathrm{pi}, \ldots, \mathrm{pn}\}, \mathrm{ti}$ and $\mathrm{pi}$ is the key words required by task and product Structure.

\section{Knowledge model integrating context}

Knowledge is an object, a kind of process and an experience ${ }^{[10]}$. Object refers to the knowledge content, process refers to the context of the knowledge activities and experience is the feeling in the using of the object to solve the problem and get certain goal. So context is the condition, background and environment related to the knowledge and knowledge activities. Knowledge can be valuable only under certain context. To distinguish and identify the different knowledge and knowledge activity effectively ${ }^{[11]}$, promote the understanding and effective application of knowledge, this paper buildsa knowledge model integrating context according to the process of theproducts development. The related context is shown in Fig.4.

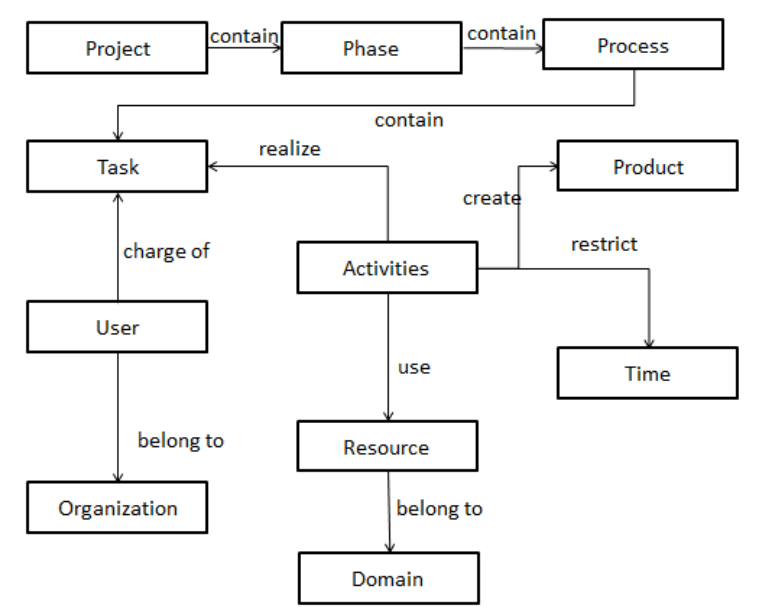

Fig.4. The context information of product development

The development process is shown in Fig.5 and the hierarchical model of the development process is shown in Fig.6. According to the context information of product development, the complex product development process and the hierarchical model, the context information of the development process can be defined as follows:

KContent $=\{$ Project, Phase, Process, Task, Activity, Product, Resource, User, Regulation\}

Activity is the smallest relatively independent unit task in the Process of product development, Task is a process unit of certain area, process is composed by a series of tasks which make the information, resources and system into a dynamic link, Phase is the highest unit in the process of the product development, Project is the name of the project, Resource is the object using and consuming in the process to finish the Activity or Task, Regulation is the relationship between different objects, User refers to the participant of the activities and related information, such as their experience, knowledge and so on.

To make the combination of knowledge and the complex product development process, this paper constructed a knowledge model integrating context based on the context information and the knowledge content is shown in Fig.7, knowledge model integrating context can be formalized as:

\section{$\mathrm{KAIC}=\{$ KContent,KContext,KRelation $\}$}

KContext is the context information in the process of product development, KContent is the content of the knowledge and KRelation is the relationship between the context and knowledge content.

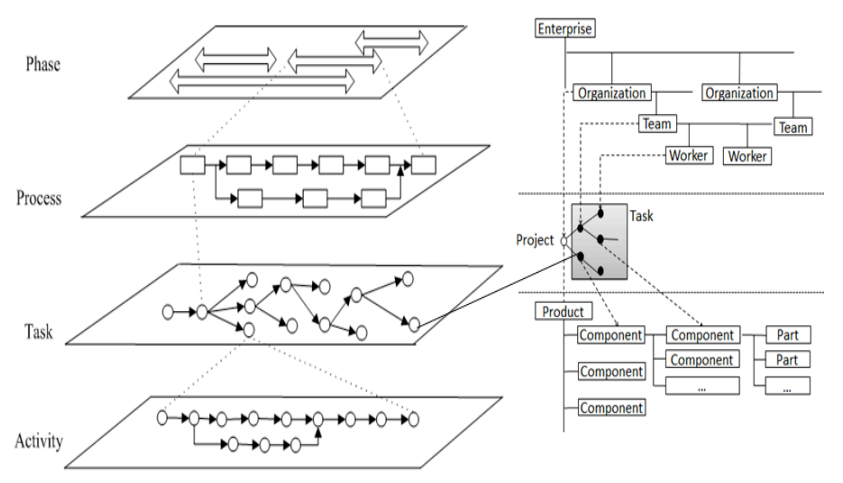

Fig.6. Hierarchical model of the development process

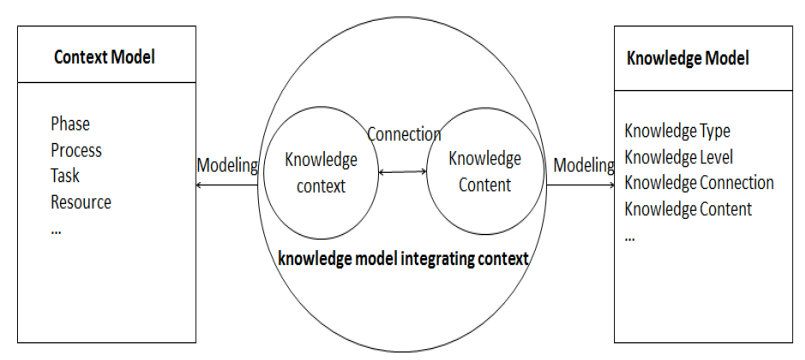

Fig.7. Knowledge model integrating context

\section{Intelligent knowledge map construction}

\subsection{Intelligent knowledge map model}

Knowledge map is a model describes knowledge objects from knowledge level which organizes the knowledge units and described in form of visual nodes. A node represents a knowledge units or the context information. For better support to resolve the problems arising in the product development process, this paper constructs knowledge map from the knowledge connections on different knowledge dimensions and visualization techniques ${ }^{[12]}$.

Intelligent knowledge map is divided into four tiers: Database Layer, Information Integrated Layer, Logic Layer, Application Layer which is shown in Fig.7. Database Layer is the data comes from different application system. Information Integrated Layer integrated knowledge from different system and combined the knowledge with the context information. The information is labeled via metadata. Logic Layer wares the contextual information such as product structure and task information to get the knowledge requirement and then obtain the knowledge directory which is needed for current activities, and the relations between the knowledge points through connection analysis. The Presentation Layer displays the knowledge points and their relations from different dimensions using visualization technology. Knowledge map is made up of 
knowledge points, knowledge connections and knowledge links.

$\ominus$ Knowledge node. It is the knowledge points and the context elements or attributes information related to it, such as key words and so on.

$\ominus$ Knowledge connection. It represents the relationship between the nodes.

$\circledast$ Knowledge link. It provides the mapping for the nodes to its detail information.

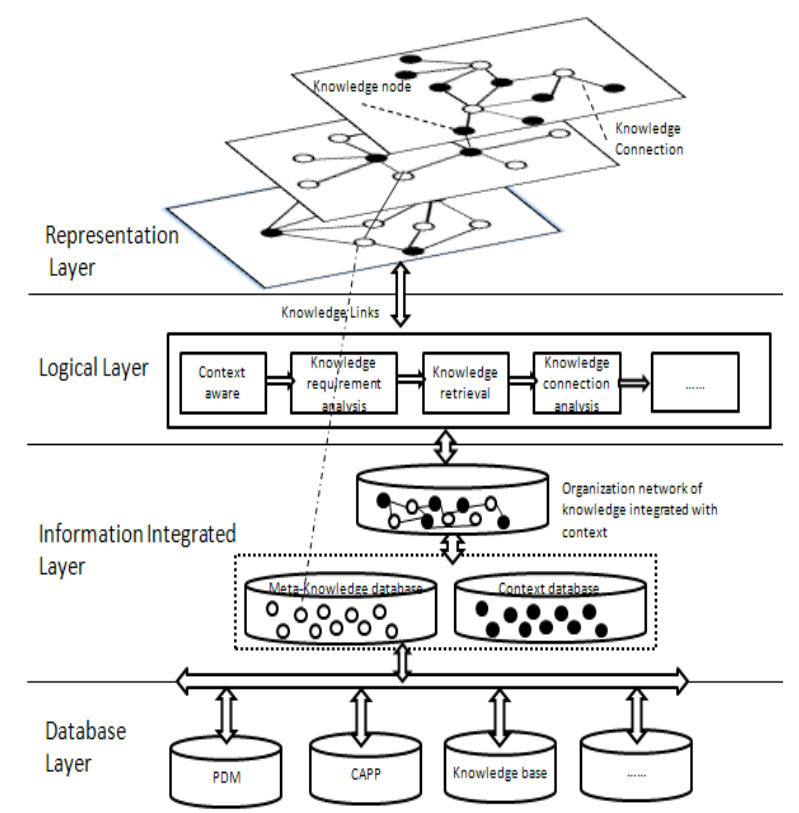

Fig.7. Layered model of knowledge map

\section{2 knowledge retrieval}

To get the knowledge units which are useful for current activities, this paper analyzes the knowledge requirement from different context dimension, builds the Knowledge model integrating context and compares the similarity between the knowledge requirements and knowledge units. In order to calculate the similarity to express the context information related to current activities as follow:

$\mathrm{U}_{n x r}=\left\{\begin{array}{lllll}W_{11}^{\prime} & W_{12}^{\prime} & \ldots & \ldots & W_{1 r}^{\prime} \\ W_{21}^{\prime} & W_{22}^{\prime} & \ldots & \ldots & W_{2 r}^{\prime} \\ & & \ldots & & \end{array}\right\}$

$W_{i j}^{\prime}=\left(\mathrm{w}_{i j}^{\prime}, \mathrm{f}_{i j}^{\prime}\right), \mathrm{f}_{i j}$ is the weight of the topic $\mathrm{w}_{i j}^{\prime}$ in the knowledge points.

The following is the formula to calculate the similarity between the knowledge units and knowledge requirements.

$$
\begin{aligned}
& \operatorname{Sim}\left(U_{n \times r}, \mathrm{KR}\right)=\partial \operatorname{Sim}\left(U_{n \times r}, \operatorname{TaskR}\right)+\beta \operatorname{Sim}\left(\mathrm{U}_{n \times r}, \operatorname{ProductR}\right) \\
& =\alpha \frac{\sum_{i=1}^{\mathrm{r}} \mathrm{f}_{\mathrm{Ti}}{ }^{*} \mathrm{f}_{\mathrm{Ti}}}{\sqrt{\sum_{i=1}^{\mathrm{r}} \mathrm{f}_{\mathrm{Ti}}^{2}} \sqrt{\sum_{i=1}^{\mathrm{r}} \mathrm{f}_{\mathrm{Ti}}^{2}}}+\beta \frac{\sum_{i=1}^{\mathrm{r}} \mathrm{f}_{\mathrm{Si}}{ }^{*} \mathrm{f}_{\mathrm{Si}}^{\prime}}{\sqrt{\sum_{i=1}^{\mathrm{r}} \mathrm{f}_{\mathrm{Si}}^{2}} \sqrt{\sum_{i=1}^{\mathrm{r}} \mathrm{f}_{\mathrm{Si}}^{2}}}
\end{aligned}
$$

Among them, $\partial$ and $\beta$ is the weight of the knowledge needs of task and product structure. The greater of the
$\operatorname{Sim}\left(U_{n x r}, \mathrm{KR}\right)$, the more in line with the current context requirements. After that sort the calculated results by the similarity between the knowledge points and the knowledge structure of the staff. The calculation method is similar to the process of calculating the similarity between the knowledge points and knowledge needs.

\subsection{Knowledge connection}

Knowledge connections are the correlations between the knowledge nodes which make the correlative nodes to form a network. Contiguity theory from psychology considers that the objects once felt together are usually related together, so that at the thought of one of them, the others will be recalled in the order that they once occurred at the same time in. Based on that theory, this paper considered the cooccurrence of the key words, knowledge points, and knowledge owner, through the algorithm of Aprior, Naive Bayes classifier and the model of ACR-R to mine the potential and implicit relationship between the knowledge, and then using the key words, knowledge points and knowledge owner as the nodes, the relationship between them as the edges, combining with the research of supernetwork to construct the intelligent knowledge map to solve the problems of difficult constructing of the knowledge map and hard to satisfy the knowledge requirements at different context.

The process of analyzing the knowledge connection is shown as bellows:

$\ominus$ Using the knowledge points getting from the knowledge retrieval based on multiple context similarity as the primary data.

$\ominus$ Obtain the key words and knowledge owners related to the knowledge points.

$\circledast$ Based on the knowledge database and the basic data obtained in the previous steps, using the Aprior algorithm to do the co-occurrence analysis of the knowledge points, key words and the knowledge owners.

(4) Calculating the distance between different nodes using the Naive Bayes classifier.

(5) Based on the theory of super-network and multidimensional knowledge visualization method to construct the knowledge map, the knowledge points, key words and knowledge owners are the node and their relationships are the edges.

(6) According to the cognitive psychology ACR - R model to navigate the cognitive process intelligently to form the intelligent knowledge map.

\subsection{The procedure of knowledge map construction}

In order to combine knowledge map with the requirements in the product development process, so as to improve work efficiency, this paper adopts the object-oriented approach and metadata technology to model and store the knowledge objects and constructs domain ontology to label them. Computers can analyze users' requirements according to their current contextual information, search the metaknowledge base, extracts the related knowledge nodes and draws the objects and their relations from multiple dimensions using the drawing engine. The procedure of knowledge map construction is as follows: 

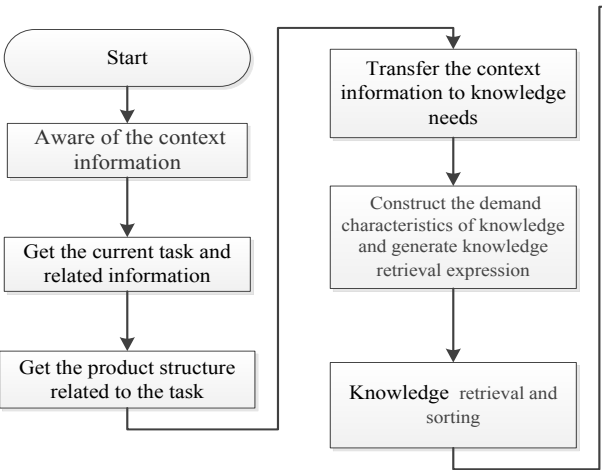

Fig.8. Steps of constructing knowledge map

\section{Examples}

In the process of complex product design, the workers need to acquire the knowledge which is useful for his current activities to avoid repeat work. And his need is changing with the task and other context, so there is a need to analysis the worker's current context information to get the knowledge requirement so as to obtain the knowledge points and keep the work going on smoothly.

This paper developed a knowledge management prototype system and established a module of knowledge map. The knowledge units are annotated in the system to form the index of the knowledge database, as shown in Fig.9, and taking the design of landing gear as an example to construct the intelligent knowledge map.

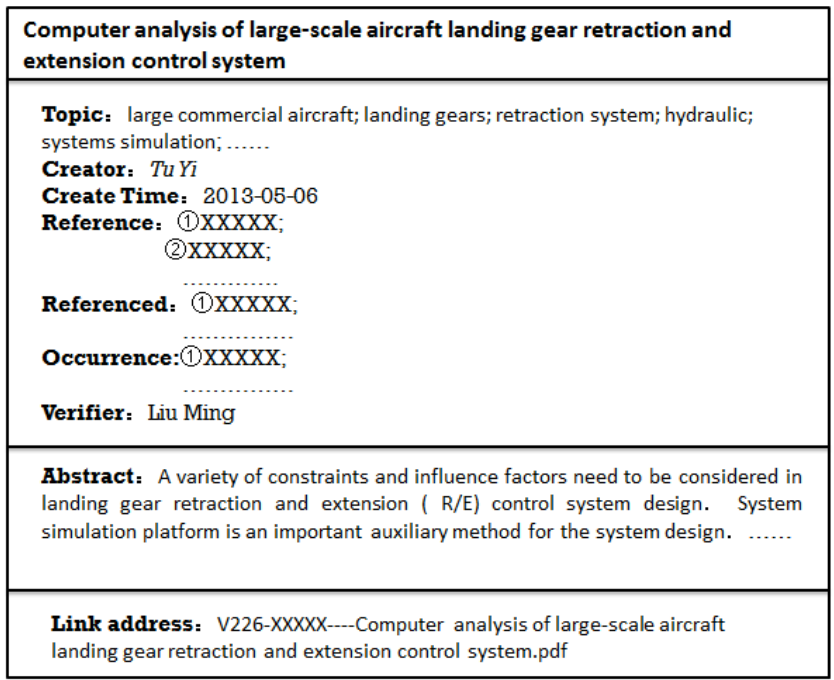

Fig.9. Knowledge annotation

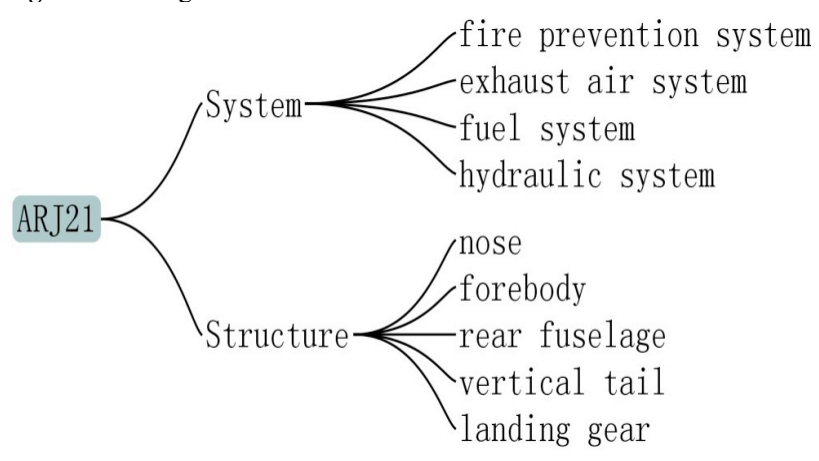

Fig. 10. Product Tree

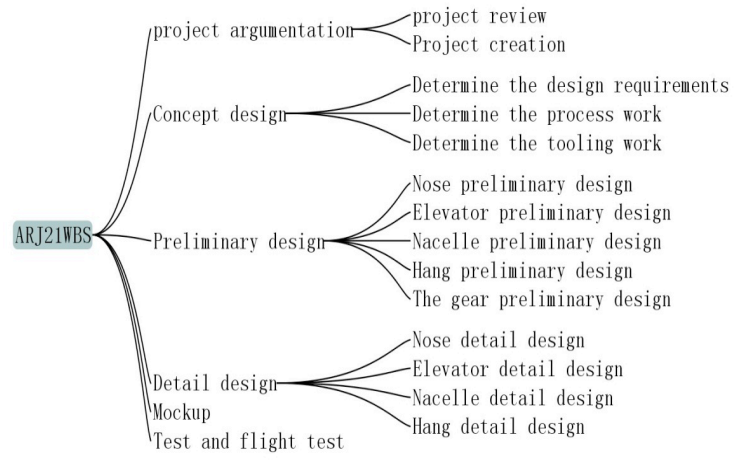

Fig.11. Project Tree

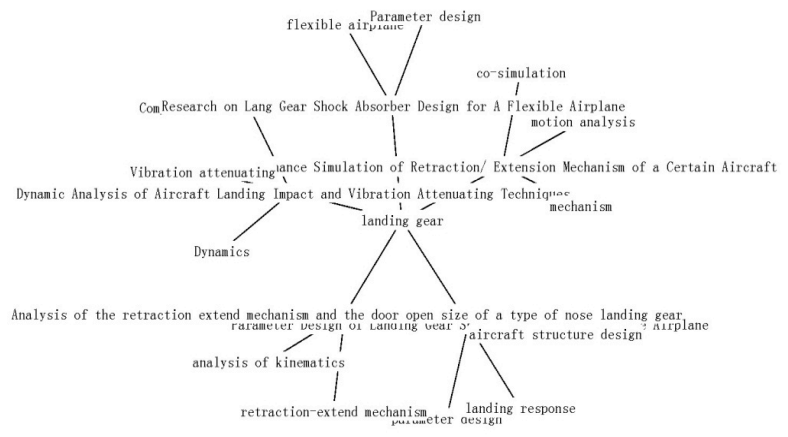

Fig.12. Super network between the knowledge points and topics

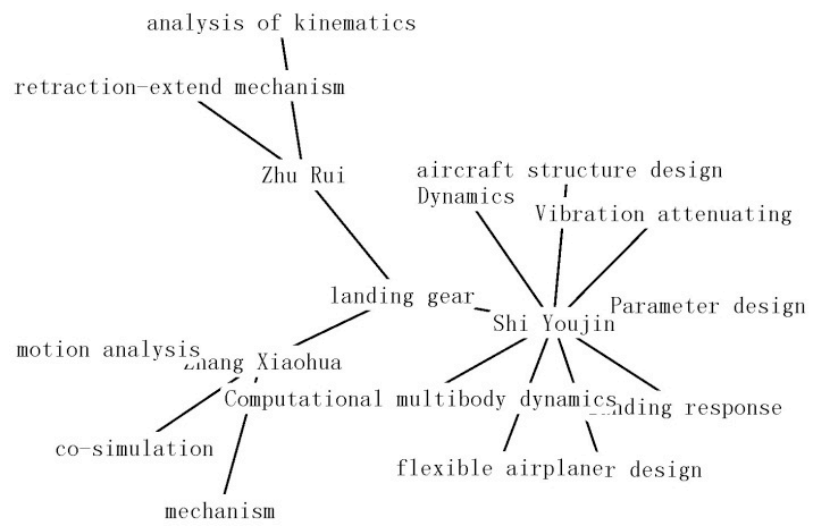

Fig.13. Super network between the knowledge owners and topics

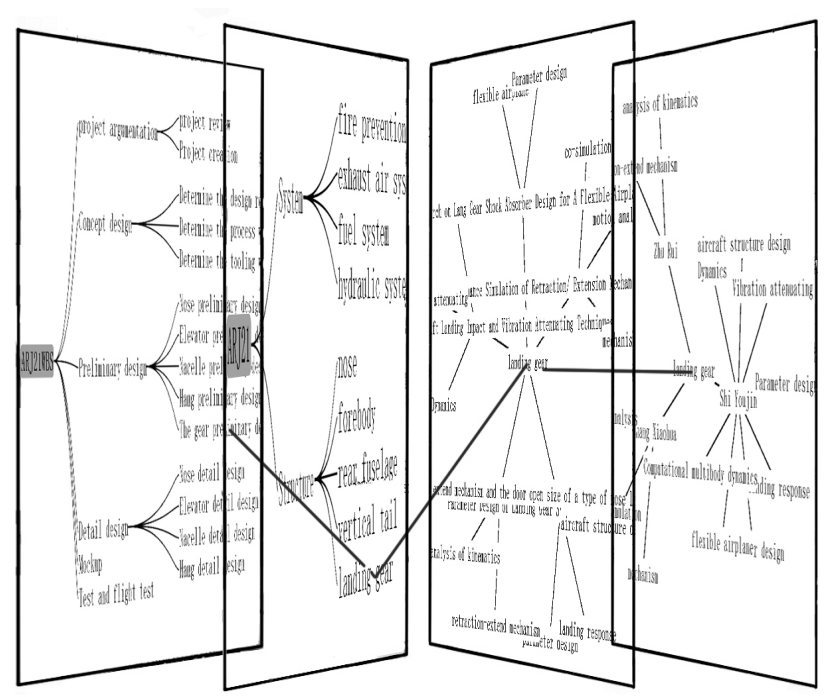

Fig.14. Intelligent knowledge map of landing gear 
Fig. 10 is the product structure tree and Fig.11 is the task tree. The prototype system obtains the knowledge directory by analyzing the context information of the task and product structure, and gets the set of knowledge points as shown in table 1. Fig. 12 is the Super network based on the knowledge points, topics and the relationship between them, Fig.13 is based on the relationship between the knowledge owners and topics. From the knowledge retrieval and analyzing the relationships between the knowledge objects from different dimensions, the multi-dimensional dynamic intelligent knowledge map of the landing gear is construct and shown in Fig. 14.

Table 1. Set of Knowledge Points

\begin{tabular}{|c|c|c|}
\hline Name of Knowledge Points & Topics & Knowledge owner \\
\hline $\begin{array}{c}\text { Research on Lang Gear Shock } \\
\text { Absorber Design } \\
\text { for A Flexible Airplane }\end{array}$ & $\begin{array}{c}\text { flexible airplane, landing gear shock } \\
\text { absorber, parameter design }\end{array}$ & Shi Youjin \\
\hline $\begin{array}{c}\text { Dynamic Analysis of Aircraft } \\
\text { Landing } \\
\text { Impact and Vibration Attenuating } \\
\text { Techniques }\end{array}$ & $\begin{array}{c}\text { Landing gear, Dynamics, Vibration } \\
\text { attenuating, } \\
\text { Computational multibody dynamics, }\end{array}$ & Shi Youjin \\
\hline $\begin{array}{c}\text { Analysis of the retraction extend } \\
\text { mechanism } \\
\text { and the door open size of a type of } \\
\text { nose } \\
\text { landing gear }\end{array}$ & $\begin{array}{c}\text { nose landing gear, retraction-extend } \\
\text { mechanism, analysis of kinematics }\end{array}$ & Zhang Rui \\
\hline $\begin{array}{c}\text { Performance Simulation of } \\
\text { Retraction/ Extension } \\
\text { Mechanism of a Certain Aircraft }\end{array}$ & $\begin{array}{c}\text { ret raction/ ex tension mechanism, co- } \\
\text { simulation, landing gear, mot ion analysis }\end{array}$ & Zhang Xiaohui \\
\hline $\begin{array}{c}\text { Parameter Design of Landing Gear } \\
\text { Shock Absorber for Flexible Airplane }\end{array}$ & $\begin{array}{c}\text { aircraft structure design; landing gear; } \\
\text { parameter design; landing response; } \\
\text { flexible air - } \\
\text { plane; energy dissipating }\end{array}$ & Shi Youjin \\
\hline ... & ... & ... \\
\hline
\end{tabular}

\section{Conclusion}

For the purpose of solving the problems of knowledge overflow and knowledge treks, this paper proposed a method to construct the intelligent knowledge map of complex product development and verified it through an instance. This method can solve the difficulty to construct a full set of knowledge map and satisfy the requirement of the work. It can make users focus on the knowledge which is useful to the current activities to improve the work efficiency.

A further research can be done in the following aspects about this paper: $\Theta$ the method of mapping the context information to the knowledge units. This paper mainly analyzes the context information of the task and product structure. A future research should be done to get the knowledge requirement more accuracy; $\ominus$ the connection between the knowledge objects. This paper proposed a method to analyze the relationship between the knowledge objects from the co-occurrence but didn't consider much about the semantic similarity between them, that's the work we need to do to make the intelligent map more intelligent and accuracy.

\section{Acknowledgements}

This study is sponsored by the the High Technology Research and Development Program(No.2009AA043302).

\section{References}

1. Shi Meihong, Wang Ting, Chen Yongdang, et al.: Knowledge push system based on business process and knowledge need[J]. Computer Integrated Manufacturing Systems, 2011, 17(4): 882-887.

2. Wei J D, Chen J Y, Tung T Y, et al.: Integration of a Concept Map Generator and a Knowledge-Portal-Based E-learning System[C]. Computer Science and Information Engineering, WRI World Congress, Washington D C, 2009: 356-360.

3. Mike U, Michael G. Ontologies: Principles, Methods and Applications[J]. The Knowledge Engineering Review, 1996, 11(2): 93-136.

4. Liao Shu-hsien.: Knowledge Management Technologies and Applications-Literature Review from 1995-2002[J]. Expert System with Applications, 2003, 25(2): 155-164.

5. Yun G, Shin D, Kim H, et al.: Knowledge-mapping model for construction project organizations $[\mathrm{J}]$. Journal of Knowledge Management, 2011, 15(3): 528-548.

6. Driessen S, Huijsen W O, Grootveld M.: A framework for evaluating knowledge-mapping tools[J]. Journal of Knowledge Management, 2007, 11(2): 109-117.
7. Irani Z, Sharif A, Kamal M M, et al.: Visualising a knowledge mapping of information systems investment evaluation[J]. Expert Systems with Applications, 2014, 41(1): 105-125.

8. Kim S, Suh E, Hwang H.: Building the knowledge map: An industrial case study[J]. Journal of Knowledge Management, 2003, 7(2): 34-45.

9. Su Hai, Jiang Zuhua, Wu Hongwei.: Building Knowledge Map for Product Development[J]. JOURNAL OF SHANGHAI JIAOTONG UNIVERSITY, 2005, 39(12): 2034-2039.

10. Yang Tao, Xiao Tianyuan, Zhang Lin.: Context-centered design knowledge management[J]. Computer Integrated Manufacturing Systems, 2004,10(12): 1541-1545.

11. Yang Yanpu, Yu Suihuai, Chen Dengkai, et.: Complex Product Virtual Maintenance Training Method Based on Knowledge Map[J]. Computer Integrated Manufacturing Systems, 2013, 21(2): 209-214.

12. Michalos M, Tselenti P, Nalmpantis S L. Visualization Techniques for Large Datasets[J]. Journal of Engineering Science and Technology Review, 2012, 5(1): 72-76. 